\title{
Anxiety and depression among university students during the lockdown: their protective and risk factors
}

\author{
Kususanto Ditto Prihadi ${ }^{1}$, Sheng Yee Wan', Valerie Yen Yee Lee $^{3}$, Hairul Nizam Ismail ${ }^{3}$ \\ ${ }^{1}$ Department of Psychology, Faculty of Social Science and Liberal Arts, UCSI University, Kuala Lumpur, Malaysia \\ ${ }^{2}$ Department of Psychology, Faculty of Behavioral Science, HELP University, Kuala Lumpur, Malaysia \\ ${ }^{3}$ School of Educational Studies, Universiti Sains Malaysia, Penang, Malaysia
}

\begin{tabular}{l} 
Article Info \\
\hline Article history: \\
Received Aug 18, 2021 \\
Revised Nov 9, 2021 \\
Accepted Nov 22, 2021 \\
\hline
\end{tabular}

Keywords:

Anxiety

Depression

Fear of missing out

Online learning efficacy

Perceived social support

Societal mattering

\begin{abstract}
Anxiety and depression among university students were reported to be increased during the outbreak of coronavirus disease 2019 (COVID-19). Various studies indicated that the phenomenon was triggered by the sudden enforcement of the studying-from-home (SFH) policy. Accordingly, we hypothesized that the students' online learning efficacy (OLE) predicted the upsurge of the two mental health issues. However, SFH also elevated the students' inclination towards social media (SM), and it brought further changes in some socio-psychological factors. We recruited 435 university students to respond to demographic items and the scales to measure factors such as perceived social support (PSS), societal mattering, and fear of missing out (FOMO) to test the hypothesis that OLE would no longer be a significant predictor of anxiety and depression when all the aforementioned variables are controlled for. The results of the hierarchical regression analyses supported our hypothesis on anxiety, while in predicting depression, OLE was still significant after controlling for the rest of the predictors. Societal mattering was the strongest protective factor against depression, whereas FOMO was the strongest risk factor of anxiety. Implications, limitations, and suggestions are discussed.
\end{abstract}

This is an open access article under the CC BY-SA license.

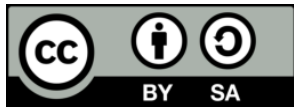

\section{Corresponding Author:}

Kususanto Ditto Prihadi

Faculty of Social Science and Liberal Arts, UCSI University

Cheras 56000, Kuala Lumpur, Malaysia

Email: ditto@usm.my

\section{INTRODUCTION}

Anxiety among university students has been prevalent for many years even before the coronavirus disease 2019 (COVID-19) outbreak. Kosic et al. [1] analyzed 68 studies on university students' anxiety between 1985 and 2017 among 22,413 participants stated that the anxiety upturn in the aforementioned period was mostly due to the escalation of the health anxiety. Their statements support the hypothesis that the escalation of anxiety among this population was caused by the presence of the pandemic itself. Confirming that, in 2021, Kosic et al. [2] published their study on 1100 participants from Italy, Romania, and Serbia, and reported higher distress following higher levels of fear of COVID-19.

Anxiety cases had been reported to be higher after the outbreak started [3], and its upturn occurred simultaneously with the upsurge of depression [4], especially among university students [5]. Confirming that, a systematic review on 40 studies conducted during the pandemic showed that the anxiety levels are averagely 24\% higher than pre-pandemic [6], and a similar situation had also been reported in the context of Malaysia [7], [8]. While anxiety is a normal response during the situations such as outbreaks [9], 
its significant upturn should be investigated, especially when it comes together with the upsurge of depression reports.

Furthermore, $30 \%$ of undergraduate students were reported to suffer from depression [10], [11], and in the context of Malaysia, the prevalence of depression among university students is considered high [12]. The prevalence was reported to be higher during the outbreak of COVID-19, as people were exposed to a higher degree of uncertainty [13]. A large sample size study $(n=44,447)$ reported the association between the outbreak and the increase of depressive symptoms [14], and most of them were reported to occur among university students [15]. The simultaneous elevation of depression symptoms and anxiety levels among university students has been recorded for decades [4], and the link was reported to be more positive during the outbreak of COVID-19 [5].

While we agree that the pandemic itself might have elevated the depressive symptoms and anxiety, we conducted this study intending to investigate some psychosocial construct that might have played some roles in the upsurge of the two mental health problems, especially among university students who must comply to the policy of studying from home (SFH). Because in the context of Malaysia, the short notice (two days) of the enforcement of the lockdown, followed by SFH, deprived all the education stakeholders of means of planning and preparation [16]. Moreover, the lockdown was prolonged into six weeks, while it was initially planned to be two weeks.

The first factor to consider is the students' belief that they can learn well through online study, or online learning efficacy (OLE). Castro and Tumibay [17] had systematically reviewed 50 studies regarding online learning, including the comparison between learning online and onsite, as well as the factors of OLE, and found 30 studies reporting that adequate OLE can only be achieved through well-planned, well-designed courses for a higher education institution. In our context, the plan and design might not have been done well due to the abrupt nature of the implementation of SFH, which might lead to less adequate OLE among the students.

Most of the students who reported higher depression symptoms levels during the outbreak also reported the perceived social isolation due to the implementation of the lockdown and SFH policies [3]. Complying to such policy was not without any challenge [8], [18]. In general, the policy of studying from home (SFH) put students into less physical social connection and higher inclination towards online social media (SM) to keep themselves connected with the larger society [19].

With the lockdown and SFH policies enforced, the usage and inclination towards SM were not only improved. SM became one of the most salient sources of social feedback, which means that the lockdown population was more exposed to and affected by more detailed information about the pandemic itself, including its social implication, fake news, hoaxes, and less-educated opinions [20], as well as perceived cyber-victimization [21], misinformation [22], and unhealthy social comparison [23], that led to negative way to accept [24]. These changes might affect some socio-psychological constructs such as how people perceived that they are supported by their society, how they matter to their society, fear of not being included or informed on what happens out there, and eventually, the way they evaluate whether their life is worth living. This current study investigated the predictive roles of the aforementioned constructs on the upturn of anxiety and depressive symptoms among university students who must comply with the SFH policy.

A systematic review on over 500 studies in two decades (1990-2011) reported that mastery experiences were stated as the most powerful source of creating a strong sense of efficacy among students, while the effectiveness of vicarious experiences was effectiveness were questioned [25]. This report led to our further understanding of the relevance of practical experience in developing learning efficacy among students. In the case of online learning, different results might apply due to the limitation of practical experiences. Students' online learning efficacy (OLE) was reported to be highly contingent upon the readiness of internet infrastructure [26], as well as the design and the preparation of the delivery [17]. Nevertheless, a more recent study indicated that despite strong infrastructure and preparation during the transition to SFH, issues such as individual readiness, academic rigor maintenance, and social-emotional wellbeing were reported to be the major hurdle for higher OLE among all the education stakeholders, including students [27].

A study on 427 Spanish university students reported that their lowered learning efficacy during the outbreak significantly predicted their anxiety levels [28], while another study on a higher size sample $(n=2,245)$ indicated similar results [29]. Furthermore, a study on 373 students in Iran reported the negative correlation between learning efficacy and depression [30], and depression among university students was reported to be increased during the pandemic [2].

Bolatov et al. [31] conducted a repeated questionnaire-based cross-sectional study on 619 students who studied onsite in 2019 (before the COVID-19 outbreak) and 798 students who had to study online in 2020 during the outbreak and reported that the link between OLE and depressive symptoms was increased despite the prevalence of the burnout syndrome, depression, anxiety, and somatic symptoms decreased after 
transitioning from onsite to online study. Thus, our first hypothesis was that OLE significantly predicts the anxiety and depressive symptoms among university students who had to SFH.

Our next hypothetical predictor is perceived social support (PSS). Zimet et al. [32] define PSS as our subjective perception that the people around us, as well as the general society, are supportive, which is not contingent upon the actual presence of social support. This construct has been established as a significant protective factor towards depression and anxiety. A systematic review on 341 studies and $\mathrm{N}=273,149$ participants suggested a significant strong relationship between PSS and depression at $\mathrm{r}=.26(95 \%$ CI $[.24, .28])$ [33]. Another meta-analytic study on 24 different studies, PSS was found to be closely associated with anxiety, with the average effect sizes between -0.36 and 0.57 [34].

A higher level of SM usage was reported to improve PSS due to the tendency of the users to intentionally attract positive social feedback by posting content that was filtered or controlled to do so [35], and the desired social feedback elicited perceived closeness between the users and their source of the feedback [36]. However, problematic SM usage, such as too frequent, too intense, or too reliant, would lead to a significant drop in PSS, followed by the increase of depressive symptoms [37]. In other words, the altered inclination towards SM during the implementation of the SFH policy might have predicted the upsurge of students' anxiety and depression [38].

The next predictor we hypothesized was societal mattering. General mattering refers to the sense that we matter to other people [39]. Societal refers to the sense that we matter to the societies we perceive we are in, such as workplace, community, churches, schools, or groups in SM [40], as opposed to interpersonal mattering, the sense that we matter to other people who matter to us [41]. Among students in a university, lower levels of societal mattering have been associated with anxiety [42], [43] and depression [44], whereas higher levels of societal mattering were found to predict students' wellbeing among university students [45] and unconditional social acceptance [24]. One plausible explanation for the contingency of students' anxiety levels towards their levels of societal mattering is that the perception of not mattering resulted in a feeling of isolation, which led them to the social avoidance apparent in social anxiety [46]. The link between mattering and depression is advocated by Flett et al. [47] who stated that higher depressive symptoms could only be found among students with a low level of mattering. Accordingly, Prihadi et al. [48] reported that societal mattering among Malaysian and Indonesian young adults significantly served as a protective factor against suicide ideation, partially mediated by depressive symptoms.

Societal mattering is contingent upon how the authority figures of the perceived community treated other individuals [40]. Contextually, apart from their regular online classrooms and announcement emails, the practice of SFH has limited students from the interaction with the university [18], which might be related to the reported increase in depression and anxiety levels. We hypothesized that social mattering, in the form of the sense of mattering to university, had played a significant role in predicting anxiety and depressive symptoms among the students.

The elevated inclination towards SM also cultivates the fear of missing out (FOMO) among young adults [49], which led them to develop an emotional state of anxiety due to the fear that one is not included in perceived positive events that others were engaged in [50]. Although SM users tend to intentionally attract positive social feedback by filtering or editing their posts [35], [51], the satisfaction of receiving the desired feedback would not last long [52], and they would be falling into another FOMO state, craving for more positive social feedback, especially when people whom they considered significant have not provided them with any desired feedback [53]. This cycle would increase the anxiety to the students who experience it, due to the absence of physical connectivity that convinces them that their peers would always be there for them without them having to check on their SM account [54].

An experimental study by Hunt et al. [55] yielded a result that when university students limited their SM usage to a healthier amount of 10 minutes per app per day led to a significant decrease in FOMO, anxiety levels, and depressive symptoms. Another study by Elhai et al. [49] confirmed the aforementioned findings by reporting that the extensive usage of SM significantly predicted depression and anxiety, with FOMO as a significant mediator. In our context, the SFH protocols led to the extensive inclination towards SM, which might lead university students to a higher FOMO level, which then might predict higher levels of anxiety and depressive symptoms.

With this current study, we attempt to explain further the association of the implementation of SFH to the reported upsurge of depression and anxiety among university students during the COVID-19 outbreak. Knowing that SFH practice might have altered some psychological constructs among our population, we hypothesized that the upturn of depressive symptoms and anxiety levels were significantly predicted by the students' lack of OLE, PSS, and societal mattering, as well as the increase of their FOMO. 


\section{RESEARCH METHOD}

\subsection{Participants}

Based on the table of Krejcie and Morgan [56], a population larger than 100,000 should be represented by at least 384 samples. Therefore, we recruited 435 participants to represent the university students in Malaysia $(n=221)$ and Indonesia $(n=214)$. The participants were aged 18 and above, 308 of them were females, 116 were males, and the remaining 11 participants prefer not to reveal their gender. All participants were studying from home, and most of them were bachelor's students $(n=382)$. They were recruited through social media platforms such as Facebook, Instagram, and Whatsapp, in which the participants had voluntarily clicked the link that allowed them access to the survey items. All participants provided their consent by clicking 'yes' in the informed consent form, which has stated that they will be giving their responses to our scales with the option to cancel their participation at any time during the process if they were to experience any discomfort.

\subsection{Materials}

Demographic items asking for the participants' basic demographic information such as nationality, gender, institutions, level of study, and mode of the current study were included. Online learning selfefficacy was measured using the online learning self-efficacy scale (OLSES) [57] with internal reliability was $\alpha=.94$. PSS was assessed using the multidimensional scale of perceived social support (MSPSS) [32] with the cronbach alpha was $\alpha=.91$. Societal mattering was measured using the societal mattering scale [58] with internal reliability was $\alpha=.92$. FOMO was assessed using the fear of missing out scale [50] with the cronbach alpha was $\alpha=.88$. Depression was measured using the Beck's depression inventory [59] with internal reliability was $\alpha=.94$. Anxiety was assessed by using the Beck anxiety inventory [9] with cronbach alpha was $\alpha=.95$.

\section{RESULTS AND DISCUSSION}

\subsection{Depression}

Table 1 illustrates the summary of the hierarchical regression of all the predictors of depressive symptoms. In model 1, OLE was entered, and the result showed that it was a significant predictor. In the model 2, 3 and 4, each of the other variable PSS, societal mattering, and FOMO was controlled for respectively.

\begin{tabular}{llccccc}
\multicolumn{6}{c}{ Table 1. Regression coefficients in predicting depression } \\
\hline \multicolumn{1}{c}{ Model } & $B$ & $t$ & Sig. & LLCI & ULCI \\
\hline 1 & OLE & -.352 & -10.123 & .000 & -.420 & -.283 \\
2 & OLE & -.223 & -6.656 & .000 & -.289 & -.157 \\
& PSS & -.345 & -10.323 & .000 & -.411 & -.280 \\
& OLE & -.166 & -4.762 & .000 & -.234 & -.097 \\
3 & PSS & -.285 & -8.185 & .000 & -.354 & -.217 \\
& Societal mattering & -.325 & -4.857 & .000 & -.460 & -.195 \\
& OLE & -.140 & -4.176 & .000 & $-.2-6$ & -.074 \\
\multirow{4}{*}{4} & PSS & -.285 & -8.507 & .000 & -.350 & -.219 \\
& Societal mattering & -.373 & -5.734 & .000 & -.501 & -.245 \\
& FOMO & .324 & 6.181 & .000 & .221 & .427 \\
\hline
\end{tabular}

*Dependent variable: Depressive symptoms

OLE, PSS, societal mattering, and FOMO significantly predicted depressive symptoms. All four predictors are considered robust because each of them was still significant after controlling for the rest of one another. The coefficient of OLE was slightly reduced each time a new predictor was controlled for. Table 1 also indicated that societal mattering was the strongest protective factor of depression, but as a risk factor, FOMO seemed to predict the increase of depressive symptoms stronger than the protective features of OLE and PSS.

\subsection{Anxiety}

Table 2 shows that OLE significantly predicted anxiety before controlling for any other predictor (model 1). Nevertheless, it became no longer significant when other variables were controlled for. On the other hand, societal mattering was insignificant before controlling for FOMO. It is also obvious that FOMO was the strongest predictor of anxiety because its positive strength towards depression was shown to be much stronger than the protective coefficients of societal mattering and PSS. 
Table 2. Regression coefficients in predicting anxiety

\begin{tabular}{|c|c|c|c|c|c|c|}
\hline \multicolumn{2}{|r|}{ Model } & B & $\mathrm{t}$ & Sig. & LLCI & ULCI \\
\hline 1 & OLE & -.152 & -3.093 & .002 & -.249 & -.055 \\
\hline \multirow{3}{*}{2} & OLE & -.055 & -1.065 & .288 & -.156 & .046 \\
\hline & PSS & -.262 & -5.096 & .000 & -.363 & -.161 \\
\hline & OLE & -.020 & -.372 & .710 & -.128 & .087 \\
\hline \multirow[t]{3}{*}{3} & PSS & -.226 & -4.124 & .000 & -.334 & -.118 \\
\hline & Societal Mattering & -.196 & -1.853 & .065 & -.404 & .012 \\
\hline & OLE & .027 & .529 & .597 & -.074 & .129 \\
\hline \multirow{3}{*}{4} & PSS & -.224 & -4.358 & .000 & -.326 & -.123 \\
\hline & Societal Mattering & -.283 & -2.823 & .005 & -.480 & -.086 \\
\hline & FOMO & .612 & 7.590 & .000 & .454 & .771 \\
\hline
\end{tabular}

\subsection{Discussion}

\subsubsection{On depression}

Our hypothesis on depression was not supported, because OLE was still significant when other variables were controlled for. Table 1 shows that individuals with adequate OLE (believe that they can learn well online) would be protected from depression, as well as those who perceived that they were socially supported and matter to their university. This finding is in line with the work of Bolatov et al. [31] related to the significant link between OLE and depression. Our results are also in line with the other studies regarding the link between other variables and depression, such as PSS [33], [37], [38], societal mattering [44], [46], [48], and FOMO [49].

Nevertheless, each time we controlled for another predictor, the coefficient of OLE was getting weaker, despite it was still a significant predictor of depression at the end of the study. This phenomenon leads to two possibilities that are worth studying in the future. First, the protective feature of OLE against depression might be conditional, it might be contingent on the levels of societal mattering, PSS, or FOMO. Thus, future research is suggested to investigate the moderating effect of PSS and FOMO towards the link between OLE and depressive symptoms. Second, it might also indicate the possibility of mediator variables that might explain the OLE-depression relationship, it is suggested for future research to include the mediation features of academic achievements, academic value beliefs, or academic resilience in future studies. Based on the pattern of the OLE's coefficient decrease, it seems to be possible for OLE to be insignificant when controlling for other factors, such as the aforementioned variables. Another possibility is that the link between OLE and depression occurred indirectly, yet the mediator variable was not included in our current study.

\subsubsection{On anxiety}

Our results supported our hypothesis that OLE would be no longer a significant predictor of anxiety when controlling for PSS, social mattering, and FOMO. It had lost its significance when PSS was the only controlled predictor (see model 2 in Table 2). This phenomenon indicated that although the students believed in their capabilities to learn well online, they might still be anxious when they did not feel supported by others, did not feel that they matter to others, or were afraid that they missed out on valuable experience from the SM. This part of our findings led us to argue that the work of Alemany-Arrebola et al. [28] and Pérez Fuentes et al. [29] related to the significant link between OLE and anxiety levels might no longer hold when considering socio-psychological factors, such as mattering, PSS, and FOMO.

On the other hand, PSS, societal mattering, and FOMO were still significant predictors of anxiety after controlling for each other, and it is in line with the previous studies that advocated the significant link between the aforementioned factors and anxiety [34], [42], [46]. However, it was also obvious that the strength of FOMO in inducing depression is much more powerful $(b=.062)$ than the protective coefficients of mattering $(b=-.28)$ and PSS $(b=-.22)$, which means that the possibility of the students being anxious while SFH is still quite high even though they believe their university cares about them and they were supported by people around them. Thus it is highly suggested to study possible protective factors against FOMO that might curb the anxiety among our population.

\subsubsection{Limitations and suggestions}

Some suggestions for future studies have been presented previously to test any certain condition for the link between OLE and depression to be significant and to find protective factors against FOMO due to its overwhelming strength in predicting anxiety. Other suggestions for future studies would be presented here due to the limitations of our study. First, we did not map the prediction of each variable into a certain domain of depression and anxiety, Therefore, it is suggested for future studies to analyze the link of each predictor to the particular depressive symptom and anxiety. Our second limitation was that we did not collect any data on 
our participants' depression and anxiety levels before the outbreak. Because depression and anxiety levels among university students had always been reported as high and prevalent even before the pandemic [1], [10], [11], we could not confirm whether the depression and anxiety levels of our participants had increased following the outbreak. We suggested that future studies might adopt a short-term longitudinal approach by collecting the data twice from the same participants, during the enforcement of SFH and after the SFH policy is lifted. Another suggestion is to conduct cross-sectional studies between students who must comply with SFH policy and those who study on-site (from different major or countries where the pandemic has already been curbed to a safe level) to investigate whether studying online truly predict students' mental wellbeing.

\section{CONCLUSION}

The objective of this current study was achieved. We discovered that the major predictor of anxiety among the students was FOMO, while societal mattering was the strongest protector of depression. Limitations and future studies have been presented and suggested respectively. As a suggestion for practical implication, our findings indicated that the authorities have a wider range of options to help students with their depression symptoms and anxiety problems. In terms of reducing depression levels, they can choose any activities to improve social mattering, show the students that they are supported, and conduct some workshops to minimize the risk of FOMO. It can all be chosen because all of the three variables significantly predicted anxiety and depression. Improving online learning skills through workshops or webinars to improve OLE might not be effective, because OLE is not a true significant predictor of anxiety, and its power to protect students from depression kept getting weaker each time another predictor is controlled.

\section{ACKNOWLEDGEMENTS} Malaysia.

This study is facilitated and funded by the School of Educational Studies (PPIP) Universiti Sains

\section{REFERENCES}

[1] A. Kosic, P. Lindholm, K. Järvholm, E. Hedman-Lagerlöf, and E. Axelsson, "Three decades of increase in health anxiety: Systematic review and meta-analysis of birth cohort changes in university student samples from 1985 to 2017 ," Journal of Anxiety Disorders, vol. 71, p. 102208, Apr. 2020, doi: 10.1016/j.janxdis.2020.102208.

[2] A. Kosic, T. Džamonja Ignjatović, and N. Petrović, “A Cross-Cultural Study of Distress during COVID-19 Pandemic: Some Protective and Risk Factors," International Journal of Environmental Research and Public Health, vol. 18, no. 14, p. 7261, Jul. 2021, doi: 10.3390/ijerph18147261.

[3] N. Vindegaard and M. E. Benros, "COVID-19 pandemic and mental health consequences: Systematic review of the current evidence," Brain, Behavior, and Immunity, vol. 89, pp. 531-542, Oct. 2020, doi: 10.1016/j.bbi.2020.05.048.

[4] N. Ghaziuddin, C. A. King, M. W. Naylor, and M. Ghaziuddin, "Anxiety contributes to suicidality in depressed adolescents," Depression and Anxiety, vol. 11, no. 3, pp. 134-138, 2000, doi: 10.1002/(SICI)1520-6394(2000)11:3<134::AID-DA9>3.0.CO;2-V.

[5] A. Debowska, B. Horeczy, D. Boduszek, and D. Dolinski, “A repeated cross-sectional survey assessing university students' stress, depression, anxiety, and suicidality in the early stages of the COVID-19 pandemic in Poland," Psychological Medicine, pp. 1-4, Oct. 2020, doi: 10.1017/s003329172000392x.

[6] J. Santabárbara et al., "Prevalence of anxiety in the COVID-19 pandemic: An updated meta-analysis of community-based studies," Progress in Neuro-Psychopharmacology and Biological Psychiatry, vol. 109, p. 110207, Jul. 2021, doi: 10.1016/j.pnpbp.2020.110207.

[7] L. S. C. Woon, M. F. I. Leong Bin Abdullah, H. Sidi, N. S. Mansor, and N. R. Nik Jaafar, "Depression, anxiety, and the COVID19 pandemic: Severity of symptoms and associated factors among university students after the end of the movement lockdown," PLoS ONE, vol. 16, no. 5 May, p. e252481, May 2021, doi: 10.1371/journal.pone.0252481.

[8] W. M. A. Wan Mohd Yunus, S. K. Z. Badri, S. A. Panatik, and F. Mukhtar, "The Unprecedented Movement Control Order (Lockdown) and Factors Associated With the Negative Emotional Symptoms, Happiness, and Work-Life Balance of Malaysian University Students During the Coronavirus Disease (COVID-19) Pandemic," Frontiers in Psychiatry, vol. 11, p. 566221, Feb. 2021, doi: 10.3389/fpsyt.2020.566221.

[9] A. T. Beck, N. Epstein, G. Brown, and R. A. Steer, "An Inventory for Measuring Clinical Anxiety: Psychometric Properties," Journal of Consulting and Clinical Psychology, vol. 56, no. 6, pp. 893-897, 1988, doi: 10.1037/0022-006X.56.6.893.

[10] J. Dinis and M. Bragança, "Quality of sleep and depression in college students: A systematic review," Sleep Science, vol. 11, no. 4, pp. 290-301, 2018, doi: 10.5935/1984-0063.20180045.

[11] A. K. Ibrahim, S. J. Kelly, C. E. Adams, and C. Glazebrook, "A systematic review of studies of depression prevalence in university students," Journal of Psychiatric Research, vol. 47, no. 3, pp. 391-400, Mar. 2013, doi: 10.1016/j.jpsychires.2012.11.015.

[12] Y. Kotera, S.-H. Ting, and S. Neary, "Mental health of Malaysian university students: UK comparison, and relationship between negative mental health attitudes, self-compassion, and resilience," Higher Education, vol. 81, no. 2, pp. 403-419, Feb. 2021, doi: 10.1007/s10734-020-00547-w.

[13] L. Flesia et al., "Predicting Perceived Stress Related to the Covid-19 Outbreak through Stable Psychological Traits and Machine Learning Models," Journal of Clinical Medicine, vol. 9, no. 10, p. 3350, Oct. 2020, doi: 10.3390/jcm9103350.

[14] Z. H. Wang et al., "Prevalence of anxiety and depression symptom, and the demands for psychological knowledge and interventions in college students during COVID-19 epidemic: A large cross-sectional study," Journal of Affective Disorders, vol.

Int J Public Health Sci, Vol. 11, No. 1, March 2022: 327-335 
275, pp. 188-193, Oct. 2020, doi: 10.1016/j.jad.2020.06.034.

[15] M. Akhtarul Islam, S. D. Barna, H. Raihan, M. Nafiul Alam Khan, and M. Tanvir Hossain, "Depression and anxiety among university students during the COVID-19 pandemic in Bangladesh: A web-based cross-sectional survey," PLoS ONE, vol. 15, no. 8 August, p. e0238162, Aug. 2020, doi: 10.1371/journal.pone.0238162.

[16] M. T. Johnson, E. A. Johnson, L. Webber, and D. Nettle, "Mitigating social and economic sources of trauma: The need for universal basic income during the coronavirus pandemic.," Psychological Trauma: Theory, Research, Practice, and Policy, vol. 12, no. S1, pp. S191-S192, Aug. 2020, doi: 10.1037/tra0000739.

[17] M. D. B. Castro and G. M. Tumibay, "A literature review: efficacy of online learning courses for higher education institution using meta-analysis," Education and Information Technologies, vol. 26, no. 2, pp. 1367-1385, Mar. 2021, doi: 10.1007/s10639019-10027-z.

[18] A. Besser, G. L. Flett, and V. Zeigler-Hill, "Adaptability to a sudden transition to online learning during the COVID-19 pandemic: Understanding the challenges for students.," Scholarship of Teaching and Learning in Psychology, Oct. 2020, doi: $10.1037 / \mathrm{st} 10000198$.

[19] S. Casale and G. L. Flett, "Interpersonally-based fears during the covid-19 pandemic: Reflections on the fear of missing out and the fear of not mattering constructs," Clinical Neuropsychiatry, vol. 17, no. 2, pp. 88-93, 2020, doi: 10.36131/CN20200211.

[20] J. J. V. Bavel et al., "Using social and behavioural science to support COVID-19 pandemic response," Nature Human Behaviour, vol. 4, no. 5, pp. 460-471, May 2020, doi: 10.1038/s41562-020-0884-z.

[21] K. D. Prihadi, Y. L. Hui, M. Chua, and C. K. W. Chang, "Cyber-victimization and perceived depression: Serial mediation of selfesteem and learned-helplessness," International Journal of Evaluation and Research in Education (IJERE), vol. 8, no. 4, pp. 563574, Dec. 2019, doi: 10.11591/ijere.v8i4.20266.

[22] S. Sood, "Psychological effects of the Coronavirus disease-2019 pandemic," RHiME, vol. 7, pp. 23-26, 2020.

[23] P. P. T. Sim and K. D. Prihadi, "Social comparison and life satisfaction in social media: The role of mattering and state selfesteem," International Journal of Public Health Science (IJPHS), vol. 9, no. 3, pp. 245-254, Sep. 2020, doi: 10.11591/ijphs.v9i3.20509.

[24] S.-Y. Kam and K. D. Prihadi, "Why students tend to compare themselves with each other? The role of mattering and unconditional self-acceptance," International Journal of Evaluation and Research in Education (IJERE), vol. 10, no. 2, p. 441, Jun. 2021, doi: 10.11591/ijere.v10i2.21238.

[25] M. Van Dinther, F. Dochy, and M. Segers, "Factors affecting students' self-efficacy in higher education," Educational Research Review, vol. 6, no. 2, pp. 95-108, Jan. 2011, doi: 10.1016/j.edurev.2010.10.003.

[26] A. Aldholay, O. Isaac, Z. Abdullah, R. Abdulsalam, and A. H. Al-Shibami, "An extension of Delone and McLean IS success model with self-efficacy: Online learning usage in Yemen," International Journal of Information and Learning Technology, vol. 35, no. 4, pp. 285-304, Aug. 2018, doi: 10.1108/IJILT-11-2017-0116.

[27] K. M. Williams and A. Corwith, "Beyond Bricks and Mortar: The efficacy of online learning and community-building at College Park Academy during the COVID-19 pandemic," Education and Information Technologies, vol. 26, no. 5, pp. 5055-5076, Sep. 2021, doi: 10.1007/s10639-021-10516-0.

[28] I. Alemany-Arrebola, G. Rojas-Ruiz, J. Granda-Vera, and Á. C. Mingorance-Estrada, "Influence of COVID-19 on the Perception of Academic Self-Efficacy, State Anxiety, and Trait Anxiety in College Students," Frontiers in Psychology, vol. 11, Oct. 2020, doi: $10.3389 /$ fpsyg.2020.570017.

[29] M. del C. Pérez-Fuentes, A. Núñez, M. del Mar Molero, J. J. Gázquez, P. Rosário, and J. C. Núñez, "The role of anxiety in the relationship between self-efficacy and math achievement," Psicologia Educativa, vol. 26, no. 2, pp. 137-143, May 2020, doi: 10.5093/PSED2020A7.

[30] M. Mirzaei-Alavijeh, S. N. Hosseini, B. Karami-Matin, and F. Jalilian, "Depression, academic self-efficacy, and achievement among college students," International Journal of Health and Life Sciences, vol. 3, no. 1, p. e74176, 2017.

[31] A. K. Bolatov, T. Z. Seisembekov, A. Z. Askarova, R. K. Baikanova, D. S. Smailova, and E. Fabbro, "Online-Learning due to COVID-19 Improved Mental Health Among Medical Students," Medical Science Educator, vol. 31, no. 1, pp. 183-192, Feb. 2021, doi: 10.1007/s40670-020-01165-y.

[32] G. D. Zimet, N. W. Dahlem, S. G. Zimet, and G. K. Farley, "The Multidimensional Scale of Perceived Social Support," Journal of Personality Assessment, vol. 52, no. 1, pp. 30-41, Mar. 1988, doi: 10.1207/s15327752jpa5201_2.

[33] S. Y. Rueger, C. K. Malecki, Y. Pyun, C. Aycock, and S. Coyle, "A meta-analytic review of the association between perceived social support and depression in childhood and adolescence," Psychological Bulletin, vol. 142, no. 10, pp. 1017-1067, Oct. 2016, doi: $10.1037 / \mathrm{bul} 10000058$.

[34] J. Guilaran, I. de Terte, K. Kaniasty, and C. Stephens, "Psychological Outcomes in Disaster Responders: A Systematic Review and Meta-Analysis on the Effect of Social Support," International Journal of Disaster Risk Science, vol. 9, no. 3, pp. 344-358, Sep. 2018, doi: 10.1007/s13753-018-0184-7.

[35] L. Bareket-Bojmel, S. Moran, and G. Shahar, "Strategic self-presentation on Facebook: Personal motives and audience response to online behavior," Computers in Human Behavior, vol. 55, pp. 788-795, Feb. 2016, doi: 10.1016/j.chb.2015.10.033.

[36] T. Oshio, H. Kimura, T. Nishizaki, and T. Omori, "Association between the use of social networking sites, perceived social support, and life satisfaction: Evidence from a population-based survey in Japan,” PLOS ONE, vol. 15, no. 12, p. e0244199, Dec. 2020, doi: 10.1371/journal.pone.0244199.

[37] C. Y. Lin, P. Namdar, M. D. Griffiths, and A. H. Pakpour, "Mediated roles of generalized trust and perceived social support in the effects of problematic social media use on mental health: A cross-sectional study," Health Expectations, vol. 24, no. 1, pp. 165173, Feb. 2021, doi: 10.1111/hex.13169.

[38] F. Johansson et al., "Depression, Anxiety and Stress Symptomatology among Swedish University Students Before and During the COVID-19 Pandemic: A Cohort Study," Scand J Public Health, vol. 49, no. 7, pp. 741-749, 2020, doi: 10.21203/rs.3.rs70620/v1.

[39] M. Rosenberg and B. C. McCullough, "Mattering: Inferred significance and mental health among adolescents," Research in community \& Mental Health, vol. 2, pp. 163-182, 1981.

[40] C. J. Schmidt, S. A. Stoddard, J. E. Heinze, C. H. Caldwell, and M. A. Zimmerman, "Examining contextual and relational factors influencing perceptions of societal and interpersonal mattering among rural youth," Journal of Community Psychology, vol. 48, no. 6, pp. 2013-2032, Aug. 2020, doi: 10.1002/jcop.22401.

[41] G. Flett, The psychology of mattering: Understanding the human need to be significant, 1st ed. Massachusetts: Academic Press, 2018.

[42] A. N. Fawwaz and K. D. Prihadi, "Studying from home and social anxiety: the role of societal and interpersonal mattering," Asia Pacific Journal of Educators and Education (in press), 2022.

[43] E. A. Moschella and V. L. Banyard, "Short measures of interpersonal and university mattering: Evaluation of psychometric 
properties," Journal of College Student Development, vol. 62, no. 1, pp. 55-71, 2021, doi: 10.1353/csd.2021.0004.

[44] K. M. Edwards and A. M. Neal, "School and community characteristics related to dating violence victimization among high school youth," Psychology of Violence, vol. 7, no. 2, pp. 203-212, Apr. 2017, doi: 10.1037/vio0000065.

[45] Z. W. Foo and K. D. Prihadi, "Happiness of university students in new normal Malaysia: The role of mattering, optimism, and social support," International Journal of Evaluation and Research in Education (IJERE), vol. 10, no. 2, pp. 448-454, Jun. 2021, doi: 10.11591/ijere.v10i2.21138.

[46] G. L. Flett, A. L. Goldstein, I. G. Pechenkov, T. Nepon, and C. Wekerle, "Antecedents, correlates, and consequences of feeling like you don't matter: Associations with maltreatment, loneliness, social anxiety, and the five-factor model," Personality and Individual Differences, vol. 92, pp. 52-56, Apr. 2016, doi: 10.1016/j.paid.2015.12.014.

[47] G. L. Flett, I. Galfi-Pechenkov, D. S. Molnar, P. L. Hewitt, and A. L. Goldstein, "Perfectionism, mattering, and depression: A mediational analysis," Personality and Individual Differences, vol. 52, no. 7, pp. 828-832, May 2012, doi: 10.1016/j.paid.2011.12.041.

[48] K. D. Prihadi, C. Y. S. Wong, E. Y. V. Chong, and K. Y. X. Chong, "Suicidal thoughts among university students: The role of mattering, state self-esteem and depression level," International Journal of Evaluation and Research in Education (IJERE), vol. 9, no. 3, p. 494, Sep. 2020, doi: 10.11591/ijere.v9i3.20587.

[49] J. D. Elhai, H. Yang, J. Fang, X. Bai, and B. J. Hall, "Depression and anxiety symptoms are related to problematic smartphone use severity in Chinese young adults: Fear of missing out as a mediator," Addictive Behaviors, vol. 101, p. 105962, Feb. 2020, doi: 10.1016/j.addbeh.2019.04.020.

[50] A. K. Przybylski, K. Murayama, C. R. Dehaan, and V. Gladwell, "Motivational, emotional, and behavioral correlates of fear of missing out," Computers in Human Behavior, vol. 29, no. 4, pp. 1841-1848, Jul. 2013, doi: 10.1016/j.chb.2013.02.014.

[51] E. A. Vogel, J. P. Rose, B. M. Okdie, K. Eckles, and B. Franz, "Who compares and despairs? The effect of social comparison orientation on social media use and its outcomes," Personality and Individual Differences, vol. 86, pp. 249-256, Nov. 2015, doi: 10.1016/j.paid.2015.06.026.

[52] S. Chugani and J. R. Irwin, "All eyes on you: The social audience and hedonic adaptation," Psychology and Marketing, vol. 37, no. 11, pp. 1554-1570, Nov. 2020, doi: 10.1002/mar.21401.

[53] F. Gioia, G. Fioravanti, S. Casale, and V. Boursier, "The Effects of the Fear of Missing Out on People's Social Networking Sites Use During the COVID-19 Pandemic: The Mediating Role of Online Relational Closeness and Individuals' Online Communication Attitude," Frontiers in Psychiatry, vol. 12, Feb. 2021, doi: 10.3389/fpsyt.2021.620442.

[54] M. Varchetta, A. Fraschetti, E. Mari, and A. M. Giannini, “Adicción a redes sociales, Miedo a perderse experiencias (FOMO) y Vulnerabilidad en línea en estudiantes universitarios," Revista Digital de Investigación en Docencia Universitaria, vol. 14, no. 1, p. e1187, Jun. 2020, doi: 10.19083/ridu.2020.1187.

[55] M. G. Hunt, R. Marx, C. Lipson, and J. Young, "No More FOMO: Limiting Social Media Decreases Loneliness and Depression," Journal of Social and Clinical Psychology, vol. 37, no. 10, pp. 751-768, Dec. 2018, doi: 10.1521/jscp.2018.37.10.751.

[56] R. V. Krejcie and D. W. Morgan, "Determining Sample Size for Research Activities," Educational and Psychological Measurement, vol. 30, no. 3, pp. 607-610, Sep. 1970, doi: 10.1177/001316447003000308.

[57] W. A. Zimmerman and J. M. Kulikowich, "Online Learning Self-Efficacy in Students With and Without Online Learning Experience," American Journal of Distance Education, vol. 30, no. 3, pp. 180-191, Jul. 2016, doi: 10.1080/08923647.2016.1193801.

[58] C. J. Schmidt, "Examining the Role of Interpersonal and Societal Mattering in the Health and Wellbeing of Rural Adolescents," Ph.D. dissertation, Department of Health Behavior and Health Education, University of Michigan, Michigan, USA, 2018.

[59] A. T. Beck, C. H. Ward, M. Mendelson, J. Mock, and J. Erbaugh, "An Inventory for Measuring Depression," Archives of General Psychiatry, vol. 4, no. 6, pp. 561-571, Jun. 1961, doi: 10.1001/archpsyc.1961.01710120031004.

\section{BIOGRAPHIES OF AUTHORS}

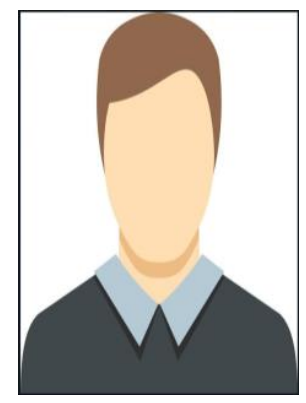

Kususanto Ditto Prihadi (iD SC SC P Head of Research and Postgraduate Studies in the Faculty of Social Science and Liberal Arts, UCSI University Malaysia. His main research interest is the psychology of mattering and self. Most of his papers in the last two years were related to role of mattering on mental health and people's wellbeing. He can be reached at email: fosslaresearch@gmail.com.

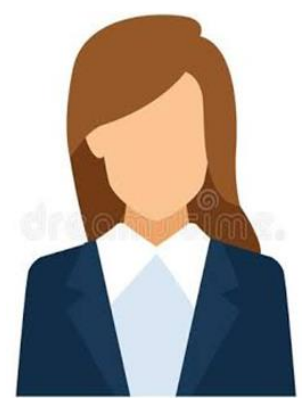

Sheng Yee Wan (D) IS SC P A Psychology graduate from HELP University Kuala Lumpur and Flinders University Australia. She was involved in many research since she was a student, and had published several papers from her research. She won the best presenter award in Malaysian International Psychology Conference (MIPC) 2021 and had her presented paper accepted to be published in a high tier journal. She can be reached at email: fosslaresearch@gmail.com. 


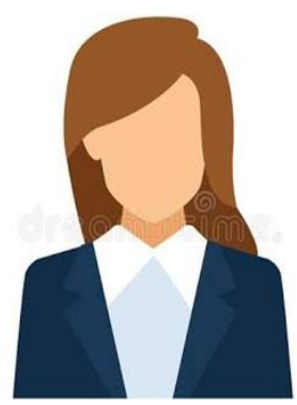

Valerie Yen Yee Lee (D) SC P She is finishing her Masters in Counseling in School of Educational Studies, Universiti Sains Malaysia, Penang. She had developed vast research interest in research since she was an undergraduate student in DISTED College, George Town. Her works so far are related to mattering, interpersonal relationships and romantic relationships. She can be reached at email: fosslaresearch@gmail.com.

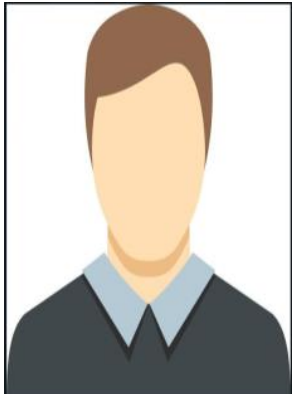

Hairul Nizam Ismail (D) $8 \mathrm{SC}$ P The Dean of School of Educational Studies, University Sains Malaysia, Penang. He has been in educational research for decades and his works in problem-based learning, as well as other area in educational psychology have been cited by hundreds of other scientists across the globe. He can be reached at email: fosslaresearch@gmail.com. 